\section{Assessment of Factors Associated with Indoor Air Pollution using Multinomial Logistic Regression: A Case Study of Barbardiya Municipality}

Chitra Raj Bhandari ${ }^{*}$ and Srijan Lal Shrestha ${ }^{2}$

Submitted: I August 2021; Accepted: 27 September 2021

Published online: 5 December 202I

DOI: https://doi.org//0.3I26/njs.v5il.4I 226

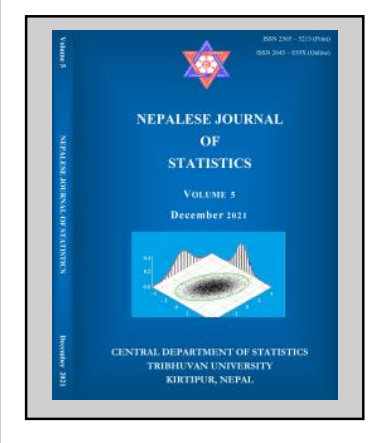

\title{
ABSTRACT
}

Background: Indoor air pollution (IAP) is a major risk factor of acute respiratory infections (ARIs). Most of the households in rural Nepal still depend upon biomass fuel. Associations between socioeconomic variables and IAP can be captured using different statistical models.

Objectives: The objective of the study was to determine association between IAP condition with socio-economic and demographic factors across the households of Barbardiya municipality, Bardiya, Nepal.

Material and Methods: Based upon the primary data of 370 households, association between IAP condition (high, moderate, low) with socio-economic and demographic variables (Ethnicity, education level, income, family size, land size etc.) were established using multinomial logistic regression model.

Results: Descriptive analysis revealed that almost $21 \%$ of the households were exposed to high (sever) IAP, 4 I \% to low and rest (38\%) were moderate. Fitted model predicted that the odds ratio of socio-economic variables like Ethnicity: Tharu community relative to Bhramin/Chhetri community was 2.5 (95\% Confidence Interval (Cl): I.08 -5.78), household head's education level: illiterate relative to literate was 8.21 (95\% Cl: 3.30-59.54), family's monthly income: $\leq$ NRs 30000 relative to > NRs 30000 was 2.38 (95\% Cl: I.10-5.16) considering high with respect to low IAP. Conclusion: Households of Tharu community have significant proportion of high and moderate levels of IAP (or household air pollution) compared to other ethnic groups. Literacy status of household head also have an association with IAP along with several other factors. Various methods can be adopted to reduce IAP which was recommended to concerned authorities.

Keywords: Indoor air pollution, multinomial logistic regression, odds ratio, population proportion to size sampling, socio-economic variables.

Address correspondence to the author: Charles Strut University, Sydney Campus, Australia. Email: bchitraraj@gmail.com* (Corresponding author email); Central Department of Statistics, Tribhuvan University, Kirtipur, Kathmandu, Nepal. Email: srijan.shrestha@cds.tu.edu.np ${ }^{2}$ Work undertaken at Central Department of Statistics, Tribhuvan University, Kirtipur, Nepal. 


\section{INTRODUCTION}

Indoor Air Quality (IAQ) has received a lot of attention in the previous several decades from the international scientific community, political institutions, and environmental governances as a way to improve the comfort, health, and welfare of building occupants. People spend about $90 \%$ of their time inside, in both private and public contexts such as homes, gyms, schools, offices, transit vehicles, and so on; consequently, indoor air quality has a substantial influence on health and quality of life, in general. The health hazards associated with indoor air pollution (IAP) or household air pollution (HAP) may be higher than those associated with outside pollution for many persons. Poor IAQ can be hazardous to vulnerable populations particularly to children, the elderly, and those suffering from chronic respiratory and/or cardiovascular illnesses. (Cincinelli \& Martellini, 2017). The government and the public in Nepal are increasingly worried about the quality of interior (household) air, and the health impacts of indoor air are becoming a significant problem particularly the rural poor households in Nepal. Other comparable studies also found similar findings. IAP (including the inhalation of acrid smoke and particles generated by the combustion of conventional biomass fuels) is believed to be the direct cause of millions of fatalities each year, with 99 percent of these deaths occurring in poor nations (World Bank, 20I I). Because biomass is widely used in Nepal, there is a serious and widespread problem of IAP. According to the 20 I I national census survey, 83 percent of Nepalese families reside in rural regions with about 92 percent of those homes using firewood for fuel (CBS, 20I2). This special issue also discussed about the connections and possible conflicts between IAQ and passive homes and/or other highly energy-efficient structures, with an emphasis on the role of ventilation systems. Between 2010 and 2012, Wallner et al. (2017) found that inhabitants of two types of buildings (mechanical vs. natural ventilation) had different health, wellbeing, and housing satisfaction results.

According to the Report on IAP and its effects on human health in Ilam District of Eastern Nepal, 2015 conducted by Nepal Health Research Council (NHRC), it was shown that 5 I percent of 600 families utilised conventional stoves, 29 percent used mixed stoves, and 20 percent used clean stoves. Similarly, over 59 percent of households utilised wood, 38 percent mixed fuel, and the remaining 3 percent used clean fuel (NHRC, 2016). According to the research done by Shrestha (2009), even if biomass fuels are utilised in mud houses, which are typical of low-income people, $\mathrm{PM}_{10}$ (Particulate matter in the air of with a diameter of 10 micrometers or less) and $\mathrm{CO}$ (Carbon monoxide) levels are considerably lowered (4I.9\% for $\mathrm{PM}_{10}$ and $70.8 \%$ for $\mathrm{CO}$ ) if ventilation is improved from poor to a better condition. As a result, the study suggested that converting to LPG or biogas fuels and constructing Concrete houses by the poor and vulnerable sections of Nepalese society could be very difficult. However, if the people strive to reduce IAP, it may be considerably reduced by improving ventilation conditions in kitchens. This can be done by making windows / doors / kitchen volume with larger dimensions with much less economic burden than the economic burden associated with the other two factors (fuel type and house type). Domestic cooking is an important factor in the exacerbation of the chronic obstructive lung disease, which affects about one-fifth of adults in rural Nepal (Pandey et al., 1990). There have 
been few published studies related to IAP and its effects on health in Nepal. Gurung and Bell (20I3) found that only 23 studies linking air pollution and health had been conducted in Nepal. Also, the generalizability among the published studies is limited due to their different study designs.

The present study has been conducted to describe the current scenario of IAP in Barabardiya municipality of Bardiya district, Nepal. This study is based upon simplest approach to find out the different magnitudes of IAP in rural settings. The concerned authorities may use the findings of this study as a reference and interested researchers can also use the findings for further research in this area.

\section{MATERIALS AND METHODS}

\section{Data and study area}

The selected study area is Barabardiya municipality of Bardiya district which lies in Lumbini Province (Province No. 5). It consists of I I Wards. This municipality is the combination of former four VDCs namely Baniyabhar VDC, Padanaha VDC, Magaragadi VDC and Dhadhawar VDC. The area covered by this municipality is $226.09 \mathrm{sq}$. $\mathrm{km}$. According to the census $20 \mathrm{II}$, the municipality consisted of 13,268 households. Among them 12,212 (92.04\%) households usually used biomass (wood/firewood/ cow dung or guitha) for cooking. The total population of this municipality was 67,952. In this municipality, 6,3 2 (3,244 males and 3068 females) children below five years of age were reported. The sample size is calculated using the Cochran's formula (Cochran, 1977) with approximately 384 households selected for survey. Two-stage cluster sampling is used with an overall response rate of $96.35 \%$. In the first stage, 3 wards are selected from II wards of Barabardiya municipality using probability proportional to size (PPS) sampling. In the second stage, children are selected using simple random sampling technique from a complete child listing and mapping of the selected wards. Excluding non-responses, the revised sample size is 370 .

\section{Study Variables}

Situation of IAP is the dependent variable in modelling. The condition of IAP could not be monitored directly due to the limitation of resources and time. As a result, situation of IAP is assessed through simplified surrogate measurement approach adopted from the study by Shrestha (2009). According to the study, IAP was categorized into three groups viz. high, moderate, and low. After reviewing various literatures related to the study, several socio-economic variables like ethnicity, gender of household head, education level of household head, religion, occupation, family type, monthly income, land size, smoking inside home are also included in the present study as independent variables.

\section{Statistical methods}

Techniques of univariate as well as bi-variate analysis are applied. Although the dependent variable is ordinal in nature, we could not fit ordinal logistic regression model because null hypothesis of parallel line test was rejected, and hence, multinomial logistic regression (MNLR) 
model is adopted. Statistical package IBM SPSS (Version. 20) is used for data analysis and model building.

\section{The multinomial logistic model}

The categories of the outcome variable, $Y$, are coded as I for high IAP, 2 for moderate IAP and 3 for low IAP.

Let, $Y_{i j}=\left\{\begin{array}{c}1, \text { if the individual fall in category } j \\ 0, \quad \text { otherwise. }\end{array}\right.$

where, $\mathrm{j}=\mathrm{I}, 2,3$, and Let, $\quad \pi_{i j}=\operatorname{Pr}\left(Y_{i j} j \mid X\right)$ denote the probability that $Y_{\mathrm{ij}}=\mathrm{j}$. Since the response categories are mutually exclusive,

$$
\sum_{j=1}^{3} \pi_{i j}=1
$$

Consider the model for $\pi_{\mathrm{i} \text { : }}$. Consider the model where their probabilities depend on a vector $X_{k}$ of covariates associated with the $i^{\text {th }}$ individuals.

$$
\ln \frac{\pi_{i j}}{\pi_{i 1}}=\ln \frac{P\left(Y_{i j}=j \mid X\right)}{P\left(Y_{i 1}=1 \mid X\right)}=\alpha_{j}+\sum_{k=1}^{g} \beta_{j k} X_{k}
$$

where $\mathrm{j}=2,3$, and $\alpha_{\mathrm{j}}$ is a constant. $\beta_{\mathrm{j} k}$, is the regression coefficient for $\mathrm{j}=2,3$ and $X_{k}(k=1,2, \ldots, g)$ are explanatory variables. The MNLR model may also be written in terms of probability $\pi_{i j}$ as follows.

$$
\pi_{i j}=\frac{e^{\alpha_{j}+\sum_{k=1}^{g} \beta_{j k} X_{k}}}{1+e^{\alpha_{j}+\sum_{k=1}^{g} \beta_{j k} X_{k}}}
$$

The parameters of this MNLR model are estimated using iteratively re-weighted least squares (IRLS) which is equivalent to the algorithm of Fisher scoring or Newton-Raphson method and leads to maximum likelihood estimates, as demonstrated by McCullagh and Nelder(1989) (Aitkin, 1996).

The overall significance of model coefficients was tested using Likelihood Ratio Test. The goodness of fit of the logistic regression model is tested by Pearson and Deviance residual analysis. Hosmer and Lemeshow Test is applied to assess the goodness of fit of the model. The degree of explanation of the variation in response variable by the covariates in the model is described using Cox \& Snell R Square and Nagelkerke R Square. In the study, Cox and Snell's R-square has been used which is based on the log likelihood of the model (LL new) and log likelihood of the original model (LL baseline) for the sample size $n$. However, this statistics measure is limited since it never reaches the theoretical maximum of I. Therefore, Negelkerke's R-square is preferred. A more useful measure to assess the utility of MNLR model is classification accuracy which compares predicted group membership based on the MNLR model to the actual known group membership which is the value of the response variable. The benchmark adopted is to characterize the MNLR model as useful if there is $25 \%$ improvement over the rate of accuracy achievable by chance alone. Omnibus Test is used to assess the significance of the coefficients of the fitted model. 


\section{RESULTS}

It was observed that out of 370 households, household having low IAP were I5I (40.8\%), moderate and high IAP were $\mathrm{I} 4 \mathrm{I}(38.1 \%)$ and $78(2 \mathrm{I} .1 \%)$ respectively. From the study of 370 households, 14 (4.I\%) households had female household head. Approximately $94 \%$ households believed on Hinduism. Terai Tribal (Tharu) are found to be $45.4 \%$, Bhramin/ Chhetri / Thakuri / Dashnami are found to be $37.3 \%$, II.6\% were Adibashi/ Janajati and remaining $5.7 \%$ were Dalit. Only $5.7 \%$ household heads were able to purse higher education (higher secondary level or above) and II.I\% of them were illiterate. Most of households (64\%) are dependent upon agriculture. In case of child's mother, nearly $96 \%$ mother's occupation is found to be agriculture/ housewife. Considering, mother's education, only II.2\% mothers were able to purse higher education (higher secondary or above) and there were 12 (3.2\%) mothers who are illiterate. $203(54.9 \%)$ children selected were first born babies, 134 (36.2\%) were second born babies, 28 (7.6\%) were third born babies and just 5 (I.4\%) were forth born babies. Among the selected children 170 (45.9\%) were males and 200 (54.1\%) were females. It is also observed that that there are some people without having own land and also there are some people having maximum 60 kathha (3 bigha) land. The half of the households under study have below 7 kathha land while one fourth of them have below 4 kathha land. The median monthly income of the households is thirty thousand, the lowest monthly income is six thousand and highest monthly income is three lakhs. There are at least 3 members and at most 24 members in a family. Similarly, it was observed that the mean age of children and their mother are 30.9 months and 22.5 years, respectively. The minimum age of mother is 14 years and one fourth of mother are of age 19, half of them are of age 22 or less and three fourth of them are of age 25 or less. It can be noted that almost half of the houses are of semi-concrete type (52.2\%), 9.5\% houses are mud houses, and $38.4 \%$ houses are concrete. Nearly $54 \%$ households are using biomass as the only source of cooking fuel. Similarly, II.1\% households are using gas only. Most of the households are using either separate room (38.1\%) or separate building (53.8\%) as a kitchen. In most of the houses, mothers serve as a regular cook at home. Most of the households were using either traditional mud stove only (54.3\%) or traditional mud stove and gas stove (34.6\%). Also, just $5 \mathrm{I}$ (13.8\%) households have well ventilation situation whereas 203 (54.9\%) and I 16 (31.4\%) have semi and ill ventilation situation, respectively. Maximum households have separate buildings for their kitchen and most of the households are using traditional mud stove.

\section{Bi-variate analysis}

Table I reveals that household head $(\mathrm{HH})$ 's religion, HH's caste, HH's education status, mother's education status, average monthly income of family, land size and room per person are statistically significant at $5 \%$ level of significance. Hence, it can be interpreted that there exist significant associations between these variables and situation of IAP. Since other variables like HH's gender, age of mother, occupation of mother and family type have $\mathrm{P}$-value greater than 0.05 they imply that null hypotheses cannot be rejected, which means that these variables are independent from situation of IAP. 
Table I. Association of situation of IAP with socio-demographic and economic characteristics.

\begin{tabular}{|c|c|c|c|c|c|}
\hline \multirow[b]{3}{*}{ Characteristics } & \multirow[b]{3}{*}{ Categories } & \multicolumn{3}{|c|}{ Situation of IAP } & \multirow[b]{3}{*}{$\mathrm{p}$-value } \\
\hline & & High & Moderate & Low & \\
\hline & & Count (\%) & Count (\%) & Count (\%) & \\
\hline \multirow[b]{2}{*}{ HH's Gender } & Male & $74(20.8)$ & 138(39.8) & $143(40.3)$ & \multirow[b]{2}{*}{0.337} \\
\hline & Female & $4(26.7)$ & $3(20.0)$ & $8(53.3)$ & \\
\hline \multirow[b]{2}{*}{ HH's Religion } & Hindu & $71(20.4)$ & 139(39.9) & 138(39.7) & \multirow[b]{2}{*}{0.015} \\
\hline & Non-Hindu & $7(31.8)$ & $2(9.1)$ & $13(59.1)$ & \\
\hline \multirow[b]{3}{*}{ HH's Caste } & Dalit/Adibashi Janajati & $26(40.6)$ & $12(18.8)$ & $26(40.6)$ & \multirow[b]{3}{*}{$<0.001$} \\
\hline & Tharu & $33(19.6)$ & $90(53.6)$ & $45(26.8)$ & \\
\hline & Bhramin/Chhetri & $19(13.8)$ & $39(28.3)$ & $80(58.0)$ & \\
\hline \multirow{2}{*}{$\begin{array}{l}\text { HH's Education } \\
\text { Status }\end{array}$} & Illiterate & $15(36.6)$ & $24(58.5)$ & $2(4.9)$ & \multirow[b]{2}{*}{$<0.001$} \\
\hline & Literate & $63(19.1)$ & $117(35.6)$ & $149(45.3)$ & \\
\hline \multirow{2}{*}{$\begin{array}{l}\text { Mother's Education } \\
\text { Status }\end{array}$} & Illiterate/ Primary & $47(31.8)$ & $53(35.8)$ & $48(32.4)$ & \multirow[b]{2}{*}{$<0.001$} \\
\hline & Above Primary & $31(14.0)$ & $88(39.6)$ & $103(46.4)$ & \\
\hline \multirow[b]{2}{*}{ Age of Mother } & Less than 20 years & $22(23.4)$ & $36(38.3)$ & $36(38.3)$ & \multirow[b]{2}{*}{0.772} \\
\hline & 20 years or above & $56(20.3)$ & $105(38.0)$ & $115(41.7)$ & \\
\hline \multirow{2}{*}{$\begin{array}{l}\text { Occupation of } \\
\text { Mother }\end{array}$} & Housewife & $74(20.9)$ & I38(39.0) & $142(40.1)$ & \multirow[b]{2}{*}{0.254} \\
\hline & Non-Housewife & $4(25.0)$ & $3(18.8)$ & $9(56.2)$ & \\
\hline \multirow{2}{*}{$\begin{array}{l}\text { Average Monthly } \\
\text { Income of Family }\end{array}$} & Upto 30,000 & $57(25.9)$ & $83(37.7)$ & $80(36.4)$ & \multirow[b]{2}{*}{0.013} \\
\hline & Above 30,000 & $21(14.0)$ & $58(38.7)$ & $71(47.3)$ & \\
\hline \multirow{4}{*}{$\begin{array}{l}\text { Own Land Size (in } \\
\text { kattha) }\end{array}$} & No own land & $20(54.1)$ & $12(32.4)$ & $5(13.5)$ & \multirow[b]{4}{*}{$<0.001$} \\
\hline & $1-4$ & $3 I(23.0)$ & $60(44.4)$ & $44(32.6)$ & \\
\hline & $5-19$ & $25(17.7)$ & $58(4 I .1)$ & $58(4 I .1)$ & \\
\hline & 20 or above & $2(3.5)$ & $11(19.3)$ & $44(77.2)$ & \\
\hline \multirow[b]{2}{*}{ Family Type } & Nuclear & $37(25.7)$ & $47(32.6)$ & $60(41.7)$ & \multirow[b]{2}{*}{0.118} \\
\hline & Joint/ Extended & $4 I(18.1)$ & $94(41.6)$ & $91(40.3)$ & \\
\hline \multirow[b]{2}{*}{ Room Per Person* } & $\begin{array}{l}\text { Less than or equal to } \\
\text { half }\end{array}$ & $49(24.9)$ & $90(45.7)$ & $58(29.4)$ & \multirow[b]{2}{*}{$<0.001$} \\
\hline & More than half & $29(16.8)$ & $51(29.5)$ & $93(53.8)$ & \\
\hline
\end{tabular}

* Room per person denotes the ratio of total number of family members to total number of rooms.

Table 2 shows that there is significant association between Ethnicity and Fuel type at I\% level of significance. Also, the proportion of Tharu households using biomass fuel only is highest (nearly two third). 
Table 2. Association of ethnicity with fuel type.

\begin{tabular}{|c|c|c|c|c|c|}
\hline \multirow{3}{*}{ Characteristics } & \multirow{3}{*}{ Categories } & \multicolumn{3}{|c|}{ Ethnicity or Caste } & \multirow[t]{3}{*}{$\mathrm{P}$-value } \\
\hline & & $\begin{array}{l}\text { Dalit/ Adabashi } \\
\text { Janajati }\end{array}$ & Tharu & $\begin{array}{l}\text { Bhramin/ } \\
\text { Chhetri }\end{array}$ & \\
\hline & & Count(\%) & Count(\%) & Count(\%) & \\
\hline \multirow{4}{*}{ Fuel type } & Biomass only & $39(19.4)$ & $137(68.2)$ & $25(12.4)$ & \multirow{4}{*}{$<0.01$} \\
\hline & Biomass(main)+ Gas & $14(13.3)$ & $23(21.9)$ & $68(64.8)$ & \\
\hline & Biomass + Gas(main) & $3(13.0)$ & $2(8.7)$ & $18(78.3)$ & \\
\hline & Gas only & $8(19.5)$ & $6(14.6)$ & $27(65.9)$ & \\
\hline
\end{tabular}

Table 3 depicts that all the variables viz. location of kitchen, regular cook at home and smoker inside home are statistically significant at $5 \%$ level of significant. Hence, it can be concluded that situation of IAP is dependent on these variables.

Table 3. Association of situation of IAP with kitchen and other characteristics.

\begin{tabular}{|c|c|c|c|c|c|}
\hline \multirow{3}{*}{ Characteristics } & \multirow{3}{*}{ Categories } & \multicolumn{3}{|c|}{ Situation of IAP } & \multirow{3}{*}{$\mathrm{p}$-value } \\
\hline & & High & Moderate & Low & \\
\hline & & Count(\%) & Count(\%) & Count(\%) & \\
\hline \multirow{4}{*}{ Location of Kitchen } & Sleeping room & 12(42.9) & $10(35.7)$ & $6(21.4)$ & \multirow{4}{*}{$0.001 *$} \\
\hline & Separate room & $36(25.5)$ & $50(35.5)$ & $55(39.0)$ & \\
\hline & Separate building & $28(I 4.1)$ & $81(40.7)$ & $90(45.2)$ & \\
\hline & Outdoor & $2(100.0)$ & $0(0.00)$ & $0(0.00)$ & \\
\hline \multirow{2}{*}{ Regular Cook at Home } & Child's mother & 63(19.4) & $122(37.7)$ & $139(42.9)$ & \multirow{2}{*}{0.04} \\
\hline & Other & $15(32.6)$ & $19(4 \mid .3)$ & $12(26.1)$ & \\
\hline \multirow{2}{*}{ Smoker Inside Home } & No & $59(24.4)$ & $82(33.9)$ & $101(41.7)$ & \multirow{2}{*}{0.03} \\
\hline & Yes & $19(14.8)$ & $59(46.1)$ & $50(39.1)$ & \\
\hline
\end{tabular}

* 3 cells $(25.0 \%)$ have expected count less than 5 . Since the percentage should not be more than $20 \%$, assumption of chi-square test is violated. For the reason Fisher's exact test is used instead of Pearson Chi-Square test.

\section{Model}

Parameter estimates of the MNLR model are shown in Tables 4 \& 5 separately regarding high versus low IAP (Model A, Table 4) and moderate versus low IAP (Model B, Table 5). Regarding Model A, except 'Dalit/Adibashi/Janajati' category of ethnicity, all variables and their categories are found statistically significant at $5 \%$ level of significance. However, for Model B, 'Dalit/Adibashi/Janajati' category of ethnicity, 'illiterate/primary' category of mother's education and 'no' category of smoking inside home are found to be statistically insignificant and remaining all variables and their categories are statistically significant at $5 \%$ level of significance. Correspondingly, odds ratio of Tharu compared to Bhramin/Chhetri is 2.497 which indicates Tharu households are 2.497 times more likely to have high IAP condition relative to low IAP condition 

compared to Bhramin/Chhetri. But risk is 3.812 times higher in Tharu households compared to Brahmin/Chhetri households regarding moderate IAP condition relative to low IAP condition.

Accordingly, education status of $\mathrm{HH}$ has significant impact on situation of IAP at $5 \%$ level of significance. As a result, the odds for illiterate $\mathrm{HH}$ having severe IAP condition (with respect to low IAP condition) is 8.209 times higher than that for literate $\mathrm{HH}$. There is also significant impact of mother's education level on situation of IAP. The odds ratio of illiterate (or up to primary educated) mother compared to mothers having higher than primary level education is $2.02 \mathrm{I}$ which indicates that the household having illiterate (or up to primary educated) mother is 2.021 times more likely to have high IAP condition relative to low IAP condition compared to households having more than primary level of education of mother. Moreover, mother's education level seems to be insignificant in Model B. However, HH's education level is significant at $5 \%$ level of significance. The odds ratio of illiterate $\mathrm{HH}$ compared to literate $\mathrm{HH}$ is 7.452 which indicates that the households having illiterate $\mathrm{HH}$ are $2.02 \mathrm{I}$ times more likely to have moderate IAP condition (relative to low IAP condition) compared to households having illiterate $\mathrm{HH}$. Also, the odds ratio of households having at most Rs. 30,000 average monthly income is I.254 which indicates that the odds for households having at most Rs. 30,000 average monthly income have severe IAP condition (relative to low IAP condition) is 1.254 times higher than that for higher income group.

Talking account of own land, the odds ratio of households without having their own land compared to households having 20 kattha or more land is 9.018 (Model A) which reveals that the household without having own land is 9.018 times more likely to have high IAP condition (relative to low IAP condition) compared to households having land size 20 kattha or more and so on for other categories. Similarly, the odds ratio of households having at most half room per person compared to households having more than half room per person is 2.664 which indicates that the households having at most half room per person is 2.664 times more likely to have high IAP condition (relative to low IAP condition) compared to households having more than half room per person. Also, in case of regular cook at home, the odds ratio of households having child's mother as regular cook compared to households having other person as regular cook is 0.159 which indicates that the households having child's mother as regular cook is nearly $86 \%$ less likely to have high IAP condition (relative to low IAP condition) compared to households having other person as regular cook. Finally, the odds ratio of households having no smoking inside house compared to households having smoking inside house is 0.619 which indicates that the households having no smoking inside house is nearly $38 \%$ less likely to have high IAP condition (relative to low IAP condition) compared to households having smoking inside house. On the contrary, this category does not show significant effect for the situation of IAP by moderate IAP related to low IAP. 
Table 4. Parameter estimates of MNLR model (Model A: high IAP relative to low IAP).

\begin{tabular}{|c|c|c|c|c|c|c|c|}
\hline \multirow{3}{*}{ Variables } & \multirow{3}{*}{ B } & \multirow{3}{*}{$\begin{array}{c}\text { S.E of } \\
\beta\end{array}$} & \multirow{3}{*}{$d f$} & \multirow{3}{*}{$\begin{array}{c}\mathrm{P}- \\
\text { value }\end{array}$} & \multirow{3}{*}{ OR } & \multicolumn{2}{|c|}{ 95\% C.I. for Odds } \\
\hline & & & & & & \multicolumn{2}{|c|}{ Ratio } \\
\hline & & & & & & Lower & Upper \\
\hline Intercept & -4.374 & 1.029 & $\mathrm{I}$ & 0.000 & & & \\
\hline \multicolumn{8}{|l|}{ Ethnicity $=$} \\
\hline Dalit/Adibashi/ Janajati & -0.003 & 0.518 & 1 & 0.995 & 0.997 & 0.361 & 2.749 \\
\hline Tharu & 0.195 & 0.429 & 1 & 0.033 & 2.497 & 1.078 & 5.784 \\
\hline \multicolumn{8}{|l|}{ Bhramin/ Chhetri ${ }^{\circledR}$} \\
\hline \multicolumn{8}{|l|}{ HH head's education } \\
\hline level Illiterate & 2.105 & 0.812 & I & 0.001 & 8.209 & 3.303 & 59.542 \\
\hline \multicolumn{8}{|l|}{ Literate $^{\circledR}$} \\
\hline $\begin{array}{l}\text { Education level of } \\
\text { mother } \\
\text { Illiterate/ Primary }\end{array}$ & 0.704 & 0.368 & 1 & 0.050 & 2.021 & 1.001 & 4.161 \\
\hline \multicolumn{8}{|l|}{ Above Primary ${ }^{\circledR}$} \\
\hline $\begin{array}{l}\text { Average monthly } \\
\text { income of family Upto } \\
\text { Rs. } 30,000\end{array}$ & 0.869 & 0.394 & 1 & 0.027 & 2.384 & 1.102 & 5.157 \\
\hline \multicolumn{8}{|l|}{ Above $30,000^{\circledR}$} \\
\hline $\begin{array}{l}\text { Own land size } \\
\text { No own land }\end{array}$ & 2.199 & 0.985 & 1 & 0.000 & 9.018 & 4.005 & 84.060 \\
\hline I-4 kathha & 1.673 & 0.829 & 1 & 0.002 & 9.018 & 5.328 & 47.718 \\
\hline 5-19 kathha & 1.779 & 0.830 & 1 & 0.001 & 5.926 & 2.864 & 44.008 \\
\hline \multicolumn{8}{|l|}{20 kathha or above ${ }^{\circledR}$} \\
\hline $\begin{array}{l}\text { Room per person } \\
\text { less or equal to half }\end{array}$ & 0.980 & 0.353 & 1 & 0.006 & 2.664 & 1.333 & 5.324 \\
\hline \multicolumn{8}{|l|}{$\begin{array}{l}\text { Room per person more } \\
\text { than half }\end{array}$} \\
\hline $\begin{array}{l}\text { Regular cook at home } \\
\text { Mother }\end{array}$ & $-1.84 \mid$ & 0.528 & 1 & 0.000 & 0.159 & 0.056 & 0.447 \\
\hline \multicolumn{8}{|l|}{ Other $^{\circledR}$} \\
\hline $\begin{array}{l}\text { Smoking inside home } \\
\text { No }\end{array}$ & -0.480 & 0.399 & 1 & 0.009 & 0.619 & 0.112 & 0.872 \\
\hline $\mathrm{Yes}^{\circledR}$ & & & & & & & \\
\hline
\end{tabular}


Table 5. Parameter estimates of MNLR model (Model B: moderate IAP relative to low IAP)

\begin{tabular}{|c|c|c|c|c|c|c|c|}
\hline \multirow[t]{3}{*}{ Variables } & \multirow{3}{*}{$\beta$} & \multirow{3}{*}{ S.E of $\beta$} & \multirow{3}{*}{ df } & \multirow{3}{*}{$\mathrm{p}$-value } & \multirow{3}{*}{ OR } & \multicolumn{2}{|c|}{ 95\% C.I. for Odds } \\
\hline & & & & & & \multicolumn{2}{|c|}{ Ratio } \\
\hline & & & & & & Lower & Upper \\
\hline Intercept & -1.980 & 0.654 & $\mathrm{~T}$ & 0.002 & & & \\
\hline $\begin{array}{l}\text { Ethnicity }= \\
\text { Dalit/Adibashi/ Janajati }\end{array}$ & -0.882 & 0.500 & I & 0.078 & 0.414 & 0.155 & 1.103 \\
\hline Tharu & 1.338 & 0.335 & I & 0.000 & 3.812 & 1.977 & 7.351 \\
\hline \multicolumn{8}{|l|}{ Bhramin/ Chhetri® } \\
\hline $\begin{array}{l}\text { HH head's education level } \\
\text { Illiterate }\end{array}$ & 2.008 & 0.778 & 1 & 0.010 & 7.452 & 1.623 & 34.225 \\
\hline \multicolumn{8}{|l|}{ Literate $®$} \\
\hline $\begin{array}{l}\text { Education level of mother } \\
\text { Illiterate/ Primary }\end{array}$ & -0.170 & 0.314 & 1 & 0.588 & 0.844 & 0.456 & 1.560 \\
\hline \multicolumn{8}{|l|}{ Above Primary ${ }^{\circledR}$} \\
\hline $\begin{array}{l}\text { Average monthly income } \\
\text { of family Up to Rs. } 30,000\end{array}$ & 0.226 & 0.293 & 1 & 0.440 & 1.254 & 0.706 & 2.227 \\
\hline \multicolumn{8}{|l|}{ Above $30,000 \AA$} \\
\hline $\begin{array}{l}\text { Own land size } \\
\text { No own land }\end{array}$ & 2.053 & 0.718 & 1 & 0.000 & 7.788 & 3.066 & 36.290 \\
\hline I-4 kathha & 1.931 & 0.456 & I & 0.000 & 6.893 & 2.772 & $|7| 4 \mid$. \\
\hline 5-19 kathha & 1.840 & 0.450 & I & 0.000 & 6.298 & 2.605 & 15.229 \\
\hline \multicolumn{8}{|l|}{20 kathha or above ${ }^{\circledR}$} \\
\hline $\begin{array}{l}\text { Room per person } \\
\text { less or equal to half }\end{array}$ & 1.152 & 0.284 & 1 & 0.000 & 3.163 & 1.814 & 5.516 \\
\hline \multicolumn{8}{|l|}{$\begin{array}{l}\text { Room per person more } \\
\text { than half® }\end{array}$} \\
\hline $\begin{array}{l}\text { Regular cook at home } \\
\text { Mother }\end{array}$ & -1.135 & 0.476 & 1 & 0.017 & 0.321 & 0.126 & 0.816 \\
\hline \multicolumn{8}{|l|}{ Other ${ }^{\circledR}$} \\
\hline $\begin{array}{l}\text { Smoking inside home } \\
\text { No }\end{array}$ & -0.137 & 0.306 & 1 & 0.927 & 0.872 & 0.534 & I.77| \\
\hline Yes® & & & & & & & \\
\hline
\end{tabular}


Model adequacy test

Table 6. Likelihood ratio test.

\begin{tabular}{llllll}
\hline \multirow{2}{*}{ Model } & Model Fitting Criteria & \multicolumn{3}{l}{ Likelihood Ratio Test } \\
\cline { 2 - 3 } & -2 Log Likelihood & Chi-Square & df & p-value \\
\hline Intercept Only & 595.077 & & & \\
\hline Final & 417.577 & 177.500 & 22 & $<0.001$ \\
\hline
\end{tabular}

Table 7. Test of goodness of fit of MNLR model

\begin{tabular}{llcc}
\hline Statistic & Chi-Square & df & p-value \\
\hline Pearson & 290.900 & 266 & 0.141 \\
\hline Deviance & 267.255 & 266 & 0.467 \\
\hline
\end{tabular}

Table 8. Hosmer and Lemeshow test of goodness of fit and Omnibus test of model coefficients.

\begin{tabular}{|llll|llll|}
\hline & \multicolumn{3}{c|}{ Hosmer and Lemeshow test } & \multicolumn{4}{c}{ Omnibus test } \\
\cline { 2 - 8 } & Chi square & df & P-value & Chi square & df & P-value \\
\hline Model A & 12.769 & 8 & 0.120 & 107.703 & II & 0.000 \\
\hline Model B & 13.501 & 8 & 0.096 & 98.924 & 11 & 0.000 \\
\hline
\end{tabular}

From Table 6, we reject the null hypothesis, and we may infer that the predictors have significant contribution to predict the response variable. Here the $\chi 2$ test for the model is significant showing the acceptable fitting of the MNLR model. Pearson and deviance residuals are not statistically significant at $5 \%$ level of significance (Table 7 ) which suggest that the estimated model fits well to the multinomial logistic regression model. The value of chi-square from Hosmer and Lemeshow test is obtained as 12.8 with its $p$-value 0.12 , which is greater than 0.05 . It verifies that there is absence of significant difference in observed and expected frequencies for both high and low groups. It means that the fitted model fits well at $5 \%$ level of significance. Similar result was obtained for model $B$ (Table 8). Also, the value of Cox and Snell's $R^{2}$ is 0.381 which indicates that $38.1 \%$ of variation in the situation of IAP is explained by the explanatory variables. However, this measure has a limitation that it never reaches its theoretical maximum of $I$. Therefore, Negelkerke's $R^{2}$ is preferred. Negelkerke's $R^{2}$ is found to be 0.433 which indicates that $43.3 \%$ of the variation in the situation of IAP is explained by the independent variables. The value of chisquare obtained from Omnibus test is found to be 107.703 with its $p$-value 0.000 which is less than 0.05 . Hence, all the coefficients of both fitted models are seen to be significant at $5 \%$ level of significance (Table 8). 
The dependent variable 'situation of IAP' is assessed by three surrogate measures of IAP viz. house type, fuel type and ventilation situation. The study found that $9.5 \%$ of households are mud built, more than half i.e., $52.2 \%$ are semi-concrete and $38.4 \%$ of households are concrete (reinforced concrete) in the study area. More than half i.e., $54.3 \%$ households are still using biomass only as their main source of cooking fuel, $28.4 \%$ households are using mainly biomass but alternatively LPG also, 6.2\% households are using mainly gas but secondarily biomass and just I I.I\% households are using only LPG as their cooking fuel. The ventilation situation of household kitchens is not found satisfactory because just $13.8 \%$ kitchens are well ventilated. The survey findings found that $40.8 \%$ of households have low condition of indoor air whereas $38.1 \%$ have moderate and $21.1 \%$ have sever condition of indoor air, which is a problematic situation. Analysis of data showed significant associations between some socio-demographic and economic characteristics and situation of IAP. Religion, ethnicity, HH education status, mother's education status, average monthly income, own land size and room per person are statistically significant at $5 \%$ level of significance. Also, location of kitchen, regular cook at home and smoking inside house are statistically significant, which shows that these variables are significantly associated with the situation of IAP. From the results of the fitted multinomial logistic regression model for explaining the situation of IAP, it can be summarized that Tharu are 2.5 times more likely to have high IAP condition relative to low IAP condition compared to Bhramin/Chhetri. Similarly, households with illiterate $\mathrm{HH}$ are 8.2 times, mothers having illiterate/ primary education level are 2.0 times, maximum monthly income Rs. 30,000 are 2.4 times most likely to have severe IAP condition (relative to low IAP condition) compared to their reference categories.

\section{CONCLUSION}

Majority of the households of Barbardiya muncipalty are still using biomass fuel as their main source of cooking fuel and only around one fifth of the houses are well ventilated. Hence, only $40 \%$ of the households are exposed to low or mild IAP. Tharu community is the most vulnerable ethnic group as most of their houses are ill-ventilated and relied upon biomass fuel. The use of biomass fuel should be minimized and the use of alternative sources of cooking fuel like biogas or LPG should be motivated. Ventilation situation of kitchen and houses is another vital aspect to reduce IAP. During construction of houses and kitchen there should be enough space to live and enough door and window sizes. Use of improved cooking stove having exhaust fan and/or vent pipe should be prioritized. Most of the households in the study are are using traditional mud stove which needs to be improved. The findings and corresponding recommendations made would be useful to concerned authorities in order to improve the IAQ of the households of Barbardiya municipality.

\section{CONFLICT OF INTEREST}

The authors declared that they have no conflict of interest. 


\section{ACKNOWLEDGEMENTS}

We would like to acknowledge all well-wishers and everyone who directly or indirectly helped us in conducting this study. The continuous support and motivation provided by the faculties and other staffs of Central Department of Statistics, TU are also highly appreciated. Mrs. Jayakala Bhandari, Mrs. Anita Sijwal, Mr. Keshav Thapa and Mrs. Kalpana Giri are also acknowledged for their help during field visit and documentation. Institutional help from district health office, Bradiya, sub-health post, Jayanagar and all female community health volunteers of Barbardiya municipality was highly appreciable.

\section{REFERENCES}

Aitkin, M. A (1996) General maximum likelihood analysis of overdispersion in generalized linear models. Stat Comput ,6, 25I-262.doi: https://doi.org/10.1007/BF00I 40869

CBS. (2012). National Population and Housing Census 201 I (National Report). Government of Nepal, National Planning Commission Secretariat, Central Bureau of Statistics (Vol. 0I). Retrieved from http://cbs.gov.np/?p=2017

Cincinelli, A., \& Martellini, T. (2017). Indoor air quality and health. International Journal of Environmental Research and Public Health, I4(II). https://doi.org/ I0.3390/ijerph I 4 I I I 286

Cochran, W. G. (1977). Sampling Techniques (Third US Edition ed.). New York: John Wiley \& Sons, Inc.

Gurung, A., \& Bell, M. L. (20I3), The state of scientific evidence on air pollution and human health in Nepal, Environmental Research, 124, 54-64, https://doi.org/10.1016/j.envres.2013.03.007.

NHRC. (2016). Indoor Air Pollution and its Effects on Human Health in Government of Nepal Report of Indoor Air Pollution and its Effects on Human Health in Ilam District of Eastern Nepal, 2015.

Pandey, M., Neupane, R., Gautam, A., \& Shrestha, I. (1990). The effectiveness of smokeless stoves in reducing indoor air pollution in a rural hill region of Nepal. Mountain Research and Development, IO(4), 313-320. doi: https://doi.org/l0.2307/3673493

Shrestha, S. L. (2009). Categorical regression models with optimal scaling for predicting indoor air pollution concentrations inside kitchens in Nepalese households. Nepal Journal of Science and Technology, 10, 205-2I I.doi: https://doi.org/I0.3 I 26/njst.v10i0.2962

Wallner, P., Tappler, P., Munoz, U., Damberger, B., Wanka, A., Kundi, M., \& Hutter, H. P. (2017). Health and wellbeing of occupants in highly energy efficient buildings: A field study. International Journal of Environmental Research and Public Health, 14(3), 314. doi: https://doi.org/10.3390/ijerph I 4030314

World Bank. (20II). Household Cookstoves, Environment, Health, and Climate Change: A New Look at an Old Problem. 
Reference to this paper should be made as follows:

Bhandari, C. R., \& Shrestha, S. L. (202I). Assessment of factors associated with indoor air pollution using multinomial logistic regression: A case study of Barbardiya municipality. Nep. J. Stat, 5, 7-20. 